\title{
The non-linear link between electricity consumption and temperature: a threshold panel approach
}

\author{
Marie Bessec, Julien Fouquau ${ }^{\dagger}$
}

October 2007

\begin{abstract}
This paper investigates the relationship between electricity demand and temperature in the European Union. We address this issue by means of a panel threshold regression model on 15 European countries over the last two decades. Our results confirm the non linearity of the link between electricity consumption and temperature found in more limited geographical areas in previous studies. By distinguishing between North and South countries, we also find that this non linear pattern is more pronounced in the warm countries. At last, rolling regressions highlight the significant impact of climate change on electricity use in Europe.
\end{abstract}

JEL Classification: C33, Q41

Keywords: Electricity demand; temperature; Panel Smooth Transition Regression models; Exponential and Logistic transitions.

*CGEMP, Université Paris Dauphine, Place du Maréchal de Lattre de Tassigny Paris France. E-mail: marie.bessec@dauphine.fr

†Corresponding author. LEO, Université d'Orléans. Faculté de Droit, d'Economie et de Gestion. Rue de Blois - BP6739. 45067 Orléans Cedex 2. E-mail: julien.fouquau@univ-orleans.fr.

We would like to thank C. Hurlin and G. Celik for their helpful comments and suggestions. All remaining errors are ours. 


\section{Introduction}

Energy related questions took a great part in the construction of the European Union. The treaties establishing the European Coal and Steel Community in 1951 and the European Atomic Energy Community in 1957 laid the foundations for the European Economic Community and later the European Union.

In the recent period, energetic questions were enhanced in the European Union with the decision to introduce a mandatory and comprehensive European energy policy at the meeting of the European Council in October 2005 in London. Following this decision, the European Commission published in March 2006 a Green Paper "A European Strategy for Sustainable, Competitive and Secure Energy" in order to develop a common European Energy Policy. As a result, the first proposals, "Energy for a Changing World" were published by the European Commission in January 2007. Many of the proposals are designed to limit global temperature changes to no more than $2^{\circ} \mathrm{C}$ above pre-industrial levels, below the temperature judged to cause a "dangerous global warming".

In line with these challenges, this paper focuses on the European electricity demand and on the potential impact of climate change on energy use. More specifically, we explore the effect of climate variables on energy demand by analysing the direct impact of temperature on the electricity consumption of 15 European countries. This choice is motivated by the important share of energy devoted to heating and cooling purposes. Hence temperature is a major determinant of electricity consumption. Moreover, this question is currently of crucial concern given the observed climate change. Globalwarm warming has already made the world $0.6{ }^{\circ} \mathrm{C}$ warmer. Exploring the link between electricity use and temperature is important to assess the impact of climate change on energy demand.

This study is complicated by the non-linear pattern of the relationship between electricity consumption and temperature. In winter, the expected link between electricity demand and temperature is negative since an increase in temperature diminishes the need for energy resources used for heating purpose. This negative response is referred to as the heating effect in the related literature. In contrast in summer, a temperature increase may raise the demand for electricity. An increase in temperature leads to a higher use of air 
conditioners and other cooling devices. This is the so-called cooling effect. Taking into account this non linearity requires a specific treatment.

Most of the existing literature dealing with the link between electricity demand and temperature captures this non linearity by using heating degree days and cooling degree days (HDD and CDD hereafter) variables (Al-Zayer and Al-Ibrahim, 1996, Sailor and Muñoz, 1997, Valor et al., 2001, Sailor, 2001, Pardo et al., 2002, Amato, 2005). This method has some drawbacks. The definition ${ }^{1}$ of the HDD and CDD variables relies on an arbitrary choice of threshold values ${ }^{2}$, generally set to $18.3^{\circ} \mathrm{C}$ (or $\left.65^{\circ} \mathrm{F}\right)^{3}$. Such a value may not be sensible for the European countries. Moreover, it is more interesting to directly consider the temperature level in the model to study the sensitivity of electricity demand to temperature.

In this paper, we adopt the method used more recently by Moral-Carcedo and VicénsOtero (2005) in their analysis of the effect of temperature on electricity demand in Spain. In this study, the authors use a logistic smooth threshold regression model (LSTR) with temperature as a threshold variable. It allows the relationship between consumption and temperature to depend on the level of the threshold variable i.e. the temperature. This approach has several advantages. The threshold value is estimated rather than being imposed a priori. It also allows a smooth transition from the cold regime to the warm one. This is relevant since there is a neutral zone for mild temperatures where the demand is inelastic to the temperature. Moreover, the impact of temperature can be assessed more easily since the variable is directly considered as an explanatory variable in the model.

One innovation of this paper is the application of this approach to a panel of 15 mem-

\footnotetext{
${ }^{1} \mathrm{CDD}$ and $\mathrm{HDD}$ variables are usually defined as $\mathrm{CDD}=\max \left(T_{t}-T^{\star}, 0\right)$ and $\mathrm{HDD}=\max \left(T^{\star}-T_{t}, 0\right)$ where $T^{\star}$ is the reference temperature.

${ }^{2}$ A notable exception is the study by Amato et al. (2005), choosing the threshold value producing the highest coefficient of determination in the regression including HDD and CDD variables.

${ }^{3}$ Alternative threshold values are sometimes considered: $21^{\circ} \mathrm{C}$ for the state of Florida in Sailor and Munoz (1997) and Sailor (2001), $10^{\circ} \mathrm{C}$ and $25^{\circ} \mathrm{C}$ for Israel in Beenstock et al. (1999), $18^{\circ} \mathrm{C}$ and $22^{\circ} \mathrm{C}$ for Cyprus in Zachariadis and Pashourtidou (2007). The two last papers include additional explanatory variables in the regression between electricity consumption and temperature such as income and energy prices.
} 
ber states of the European Union over the last two decades. To this aim, we use the non-dynamic panel smooth transition regression model with fixed individual effects introduced by Gonzàlez et al. (2005). Focusing on a panel of countries rather than on a single country permits to learn about an individual's behaviour by observing the behaviour of the others and permits to derive results on a large geographical area. This provides guidelines to formulate policy recommendations at the European scale. Considering a long-run time perspective is also relevant to measure the impact of climate change.

In this paper we also consider more general transition functions than the ones used by Moral-Carcedo and Vicéns-Otero (2005). First, we allow for more than one transition function as done by Gonzàlez et al. (2005). This provides a more accurate characterization of the transition between the cold and warm regimes. We also consider both logistic and exponential transition functions. To our knowledge, the study presented here is the first to apply a panel exponential smooth transition regression model. Although the use of the exponential transition is less intuitive, it permits to capture the lowering of the change in the link between consumption and temperature for the lowest temperatures.

Our results give an accurate characterization of the non-linear link between electricity consumption and temperature in Europe. On the whole panel, a clear heating effect is identified, whereas the cooling effect is less important than in previous studies applied to other geographical areas as the United-States, Saudi Arabia or Spain. Such a result is relevant since there are less warm days than cold days in most European countries and since the cooling devices are less developed. By distinguishing between North and South countries, we also show that the non-linear pattern is more pronounced in the warm countries than in the cold ones. We find a clear U-shaped relationship in the warmer countries, whereas the electricity demand of the colder ones is more influenced by the heating effect. Finally, rolling regressions highlights a significant impact of the climate change especially in the South countries.

The outline of this paper is as follows. The next section describes the data and the preliminary treatment of the trend and the non climatic seasonality pattern of the consumption variable. The third section introduces the model specification and the estimation methods. The fourth section presents the empirical results. The last section concludes. 


\section{The relationship between electricity demand and tem- perature}

We use data on the 15 member states of the European Union until 2004: Austria, Belgium, Denmark, Finland, France, Germany, Greece, Ireland, Italy, Luxembourg, the Netherlands, Portugal, Spain, Sweden and the United Kingdom ${ }^{4}$. Our sample covers the period 19852000. The analysis uses monthly data on electricity consumption, temperature, population and production in total manufacturing. The electricity data is provided by EUROSTAT and is expressed in gigawatts per hour (gwh). Production data is seasonal unadjusted and is taken from the OECD database. Monthly population was obtained by interpolating quarterly OECD data. Temperature data is a monthly average expressed in Celsius degrees and has been obtained from the High Resolution Gridded Dataset of the Climatic Research Unit University of East Anglia (Mitchell et al., 2004).

A limitation of our analysis is that we do not distinguish between residential, commercial and industrial demand for electricity. Residential, commercial and industrial sectors exhibit distinct demand response to temperature. Only the residential and commercial sectors demonstrate a clear sensitivity to climate variables ${ }^{5}$. We also quantify the impact of temperature change on energy consumption only at a national level. Hence, we capture an average response for a large geographic area without taking into account regional differences in temperature, in energy systems (energy sources, efficiencies, distribution systems, characteristics of end users,...) and in sectoral composition. Distinguishing sectors and regions would have been more relevant, but it was not possible to obtain disaggregate data on the 15 countries and over the whole period considered in this study.

To investigate the temperature sensitivity of electricity consumption, we have to remove the effect of non-climatic factors on this variable. In line with the previous literature

\footnotetext{
${ }^{4} 12$ new countries joined the European Union: Cyprus, Czech Republic, Estonia, Hungary, Latvia, Lithuania, Malta, Poland, Slovakia, Slovenia in 2004, Bulgaria and Romania in 2007. Because of the lack of data, we do not consider these additional countries in this study.

${ }^{5}$ See for example Bigano et al. (2006) for a discussion of this point.
} 
(Sailor and Muñoz, 1997, Pardo et al., 2002, Moral-Carcedo and Vicéns-Otero, 2005), three components are filtered out from the electricity demand:

- The demographic trend: the population of the whole area increases by $5 \%$ from 1985 to 2000 which boosts the electricity use.

- The technological trend due to the improving of energy efficiency, the expansion of air-conditioning, the changes in square footage, home insulation and in appliance usage, ...

- The monthly seasonality related to the activity: in particular, the decrease in production during the summer period leads to a reduction in the consumption which could offset the cooling effect.

We simply remove the demographic trend by dividing the consumption by the population. Then, the two last components are eliminated by applying three alternative filters (referred to as filters $\mathrm{A}, \mathrm{B}$ and $\mathrm{C}$ in what follows) to the electricity consumption per capita of each country.

First, we use the approach proposed by Moral-Carcedo and Vicéns-Otero (2005). The filtered demand $F D_{t}^{A}$ is obtained as the residuals of the OLS regression of the electricity demand on a third degree time polynomial ${ }^{6}$ and a dummy for the month of August:

$$
E_{t}=\alpha_{0}+\alpha_{1} t+\alpha_{2} t^{2}+\alpha_{3} t^{3}+\delta \mathbb{I}_{a u g, t}+F D_{t}^{A}
$$

where $E_{t}$ denotes the electricity consumption at time $t, t$ is a time variable $(t=0,1,2, \ldots)$, $\mathbb{I}_{\text {aug,t }}$ is a dummy for August which equals 1 if the $t$ observation corresponds to the month of August, 0 otherwise. The dummy variable is introduced to remove the change in consumption due to the decrease in activity during the summer holiday ${ }^{7}$. The non significant terms are discarded from the model.

\footnotetext{
${ }^{6}$ Higher order terms are generally not significant in the trend estimation.

${ }^{7}$ Moral-Carcedo and Vicéns-Otero (2005) also include a "working day effect variable" to filter out the calendar effect in the demand of a particular day, but this can not be done here because we employ monthly data.
} 
Second, we employ the filter applied by Li and Sailor (1995), Sailor and Muñoz (1997) and Sailor (2001). The filtered consumption is obtained as:

$$
F D_{y, t}^{B}=\frac{E_{y, t}}{\bar{E}_{y} / \bar{E}}
$$

where $F D_{y, t}^{B}$ refers to the filtered consumption and $E_{y, t}$ to the electricity demand in year $y$ at time $t, \bar{E}_{y}$ is the average monthly electricity consumption for year $y$ and $\bar{E}$ is the average monthly electricity consumption on the whole period. Contrary to the two other filters, this transformation removes the long-run trend in the consumption data, but does not filter out the non climatic seasonal effects. Therefore, it may appear to be less relevant. Nevertheless, it is used for the aim of comparison with previous studies.

We propose a third filter to isolate the influence of climate on electricity use. As in Moral-Carcedo and Vicéns-Otero, the electricity demand is regressed on a third-order polynomial trend ${ }^{8}$. A seasonal unadjusted production term is also included among the regressors to filter the impact of the activity. The estimated model is given by:

$$
E_{t}=\alpha_{0}+\alpha_{1} t+\alpha_{2} t^{2}+\alpha_{3} t^{3}+\delta Y_{t}+F D_{t}^{C}
$$

where $Y_{t}$ designs the seasonal unadjusted production at time $t$. Again, the non significant variables are removed from the equation. The filtered demand $F D_{t}^{C}$ is given by the residual component. This last approach can be more relevant than the use of a dummy for the month of August since the seasonal effect of the activity may not be restricted to the summer period.

Figures 1, 2 and 3 display scatter plots of the filtered consumption against the temperature in the 15 countries under study. We also report a local polynomial kernel regression of order 2 with a Gaussian kernel between the two variables ${ }^{9}$. As an illustrative example,

\footnotetext{
${ }^{8}$ Again, higher order terms are not considered because they are generally found not significant in the trend estimation.

${ }^{9}$ Local polynomial kernel regressions of order 2 fit the dependent variable $\mathrm{Y}$ at each value $\mathrm{x}$ (the grid points) by choosing the set of parameters $\beta_{i}, i=0,1,2$ to minimize the weighted sum of squared residuals: $S S R(x)=\sum_{i=1}^{T}\left(Y_{i}-\beta_{0}-\beta_{1}\left(x-X_{i}\right)-\beta_{2}\left(x-X_{i}\right)^{2}\right)^{2} K\left(\frac{x-X_{i}}{h}\right)$ where $\mathrm{T}$ is the number of observations of $\mathrm{X}$ and $\mathrm{Y}, \mathrm{h}$ is the bandwidth and $\mathrm{K}$ is a kernel function that integrates to 1 . In this study, we use a Gaussian kernel function $K(u)=\frac{1}{\sqrt{2 \pi}} \exp \left(-\frac{1}{2} u^{2}\right)$, a bandwidth $h=0.15\left(X_{U}-X_{L}\right)$ with $\left(X_{U}-X_{L}\right)$ the range of $\mathrm{X}$ and 100 grid points $x_{i}=X_{L}+i\left(\frac{X_{U}-X_{L}}{100}\right), i=0,1, \ldots, 99$.
} 
let us examine the results obtained for Greece. The relationship between the two variables is clearly nonlinear in this country. The demand increases when the temperature decreases when it is cold due to the use of heating appliances, whereas higher temperatures increase the electricity consumption to run cooling devices during the warm periods. The reversal of the curve is gradual. There is a zone around $16^{\circ} \mathrm{C}$ where the demand is insensitive to the temperature variations. Such a pattern is consistent with the approach based on a smooth transition model that we adopt in the following.

When comparing the results obtained in the 15 countries, we can identify three groups of countries whatever the filter that we apply: the cold countries ${ }^{10}$ where only the heating effect is observed (Austria ${ }^{11}$, Denmark, Finland, Sweden and the United-Kingdom), the intermediate countries where the heating effect dominates, but where a weak cooling effect is also visible (Belgium, France, Germany, Ireland, Luxembourg and the Netherlands) and the warm countries which clearly exhibit the two effects (Greece, Italy, Portugal and Spain). Note also that even in the warm countries the heating effect is more pronounced than the cooling one since there are more cold days than warm ones in the European countries and since the cooling systems are less developed. The only exception is Greece where the two effects are equally balanced.

The three filters give similar results. Yet, we note a higher dispersion in the scatter plots around the fitted polynomial when using the filters A and B (Figures 1 and 2). As far as the filter $\mathrm{A}$ is concerned, there is a higher variability of the plots for the highest temperatures in many countries (Austria, Belgium, Denmark, Finland, France, Ireland and Sweden). It could mean that the seasonal effect of the activity in summer is not completely removed by the August dummy. In Figure 2, there are many observations far above the other ones irrespective of the temperature level in most countries (Austria, Belgium, Denmark, Germany, Greece, Ireland, Italy and Portugal). These findings could suggest that the filter $\mathrm{C}$ (Figure 3) introduced in this paper is more relevant to remove the

\footnotetext{
${ }^{10}$ See Table 1, for a ranking of the countries according to the average monthly temperature from 1985 to 2000 .

${ }^{11}$ Note however that we observe a weak cooling effect in Austria when applying the filter A. This could be a spurious effect of the increase in the variability of the filtered consumption for the highest temperatures mentioned below for this filter.
} 
trend and the non climate effects from the electricity use.

\section{Methodology}

\subsection{Specification}

The results obtained in the previous section and in the earlier literature suggest that temperature does not have a linear impact on electricity consumption. Indeed, demand both increases when temperature decreases in cold period and when it increases with high temperatures. One solution to circumvent this issue is including HDD and CDD variables in the specification. However, this method requires an arbitrary choice of the threshold values. An alternative solution consists in introducing threshold effects in the linear model. This avoids the arbitrary choice of threshold values. A second advantage of this approach is to provide a parametric approach of the cross-country heterogeneity when applied to a panel of countries.

For this reason, we apply a class of panel threshold models developed by Hansen (1999) and Gonzàlez et al. (2005) to characterize the relationship between electricity use and temperature in the 15 European countries. The corresponding model with fixed effects $\alpha_{i}$ is then defined as follows:

$$
F D_{i t}=\alpha_{i}+\beta_{0} T_{i t}+\beta_{1} T_{i t} g\left(T_{i t} ; \gamma, c\right)+\epsilon_{i t}
$$

for $i=1, \ldots, N$ and $t=1, \ldots, N$, where $N$ and $T$ design the cross-section and time dimensions of the panel, $F D_{i t}$ is the filtered demand and $T_{i t}$ the monthly average temperature of the $i^{\text {th }}$ country at time $t$. The residual $\epsilon_{i t}$ is assumed to be $i . i . d .\left(0, \sigma_{\varepsilon}^{2}\right)$. To explain simply the mechanism of transition, let us consider first a brutal transition (PTR model) as in Hansen (1999). In this case, the function $g($.$) equals an indicator function:$

$$
g\left(T_{i t} ; c\right)= \begin{cases}1 & \text { if } T_{i t} \geq c \\ 0 & \text { otherwise }\end{cases}
$$

In this model, the transition mechanism between extreme regimes is very simple: at each date, if the threshold variable (i.e. the temperature) observed for a given country is smaller than a given value, called the location parameter $c$, the electricity demand of the country 
is defined by a particular model (or regime); this regime is different if the temperature is larger than this location parameter. More precisely, the coefficient of the temperature is equal to $\beta_{0}$ if the temperature is smaller than $c$ and to $\beta_{0}+\beta_{1}$ if the temperature is larger. In our application, the coefficient $\beta_{0}$ associated with colder values is expected to be negative, whereas $\beta_{0}+\beta_{1}$ prevailing in warm periods should be positive.

Even if the PTR model can be extended to a more general specification with $r$ regimes, the link between electricity consumption and temperature can be divided only into a (small) finite number of classes. Such assumption reduces the possibility of heterogeneity and may be unrealistic even for the European countries which have different characteristics of consumption. Moreover, we have seen previously that the transition from the regime where electricity demand reacts negatively to temperature increases to the regime where the response is positive is gradual rather than brutal. There is a neutral zone around mild temperatures where the demand is inelastic to temperature. It means that the regression coefficients change gradually when moving from the cold regime to the warm one. Therefore, we use a smooth transition function (PSTR model) introduced by Gonzalès et al. (2005).

As common in the literature of threshold panel data, we consider a logistic transition function (LPSTR model) but also an exponential transition function (EPSTR model) which has never been done with panel data to our knowledge. These two functions are defined as follows:

$$
\begin{aligned}
g\left(T_{i t} ; \gamma, c\right) & =\frac{1}{1+\exp \left[-\gamma\left(T_{i t}-c\right)\right]}, \gamma>0 \\
g\left(T_{i t} ; \gamma, c\right) & =1-\exp \left[-\gamma\left(T_{i t}-c\right)^{2}\right], \gamma>0
\end{aligned}
$$

The coefficient $c$ denotes a location parameter and the coefficient $\gamma$ determines the slope of the transition function. In the two cases, the transition function $g($.$) is a continuous func-$ tion bounded between 0 to 1 . Figure 4 depicts these two transition functions for various values of the slope parameter $\gamma$.

The logistic function in (6) has a S-shape. It could be used to represent a smooth transition from the cold regime (where the temperature coefficient is negative) to the warm one (where the coefficient becomes positive) with a neutral zone for mild temperatures where 
the demand is inelastic. The parameter $\gamma$ determines the smoothness i.e. the speed of the transition from one regime to the other one. When the $\gamma$ parameter tends to infinity, the transition function $g\left(T_{i t} ; \gamma, c\right)$ tends to the indicator function (equation 5) and thus the LPSTR model corresponds to the PTR model. In contrast, when $\gamma$ tends to zero, the transition function $g\left(T_{i t} ; \gamma, c\right)$ is constant and the model reduces to the standard linear model with individual effects (the so-called "within" model).

The exponential function (7) is U-shaped. Thus, in the two opposite regimes (far removed from the location parameter), the coefficient between electricity demand and temperature is assumed to be the same. At first sight, this function could appear inappropriate to model the relationship between electricity use and temperature. Indeed, the link between the two variables is clearly different for the lowest and highest temperatures. However, the values of the transition variable need not be associated to all part of the transition function. In the extreme case where the transition variable is always above the location parameter, the exponential function has an equivalent shape to that of the logistic function. Similarly, if we use two particular logistic functions in the model, a function similar to the exponential one can be obtained. Hence, these two specifications can be used to prove the robustness of the estimation results. In our application, we will obtain a less extreme case where the left part of the exponential function is partly visited. This provides a better representation of the link between electricity demand and very cold temperatures. To conclude, a drawback of this exponential function is that for either $\gamma \rightarrow 0$ or $\gamma \rightarrow \infty$ the function collapses to a constant (equal to 0 and 1, respectively). Hence, the model becomes linear in both cases and the Exponential Panel Smooth Transition Regression model does not nest the PTR model as a special case.

Regardless of the transition function selected, the PSTR model has the great advantage to allow parameters to vary across temperature and countries. More precisely, the coefficient is defined as a weighted average of parameters $\beta_{0}$ and $\beta_{1}$ :

$$
e_{i t}=\frac{\delta F D_{i t}}{\delta T_{i t}}=\beta_{0}+\beta_{1} g\left(T_{i t} ; \gamma, c\right)+\beta_{1} T_{i t} \frac{\delta g\left(T_{i t} ; \gamma, c\right)}{\delta T_{i t}}
$$

Consequently, this specification allows for an evaluation of the influence of the variable $T_{i t}$ on electricity consumption. It is important to note that the coefficient in a PSTR model can be different from the estimated parameters defined in the extreme regimes, i.e. the 
parameters $\beta_{0}$ and $\beta_{1}$, as illustrated by equation (8). Therefore, it is generally difficult to interpret directly the values of these parameters (as in a probit or logit model). It is generally preferable to interpret the sign of these parameters, which indicates $(i)$ an increase or a decrease in the coefficient depending on the value of the temperature variable and $(i i)$ the varying coefficient in the time and individual dimensions given by equation (8).

Finally, the PSTR model can be generalised to $r+1$ extreme regimes as follows:

$$
F D_{i t}=\alpha_{i}+\beta_{0} T_{i t}+\sum_{j=1}^{r} \beta_{j} T_{i t} g_{j}\left(T_{i t} ; \gamma_{j}, c_{j}\right)+\epsilon_{i t}
$$

where the $r$ transition functions $g_{j}\left(T_{i t} ; \gamma_{j}, c_{j}\right)$ depend on the slope parameters $\gamma_{j}$ and on the location parameters $c_{j}$. In this generalisation, the coefficient for the $i^{\text {th }}$ country at time $t$ is defined by the weighted average of the $r+1$ parameters $\beta_{j}$ associated to the $r+1$ extreme regimes:

$$
e_{i t}=\frac{\delta F D_{i t}}{\delta T_{i t}}=\beta_{0}+\sum_{j=1}^{r} \beta_{j} g_{j}\left(T_{i t} ; \gamma_{j}, c_{j}\right)+\sum_{j=1}^{r} \beta_{j} \frac{\delta g_{j}\left(T_{i t} ; \gamma_{j}, c_{j}\right)}{\delta T_{i t}} T_{i t}
$$

\subsection{Estimation and linearity test}

The estimation of a PSTR model consists of several stages. In the first step, a linearity test is applied and the threshold specification with one transition function is estimated. Then, if the linear specification is rejected, the optimal number of transition functions is determined by conducting tests of no remaining non-linearity.

Regardless of the choice of the transition function, the estimation of the parameters of the PSTR model requires eliminating the individual effects $\alpha_{i}$ by removing individualspecific means and then applying non linear least squares to the transformed model (see Gonzàlez et al., 2005 or Colletaz and Hurlin, 2006 for more details).

The linear model must be tested against the PSTR alternative and the number $r$ of transition functions required to capture all the non-linearity must be determined by following the testing procedure of Gonzàlez et al. (2005). Testing the linearity in a PSTR model (equation 4) can be done by testing $H_{0}: \gamma=0$ or $H_{0}: \beta_{0}=\beta_{1}$. In both cases, the test is non standard since the PSTR model contains unidentified nuisance parameters under 
$H_{0}$ (Davies, 1987). A possible solution is to replace the transition function $g_{j}\left(T_{i t}, \gamma_{j}, c_{j}\right)$ by a Taylor expansion around $\gamma=0$ and to test an equivalent hypothesis in an auxiliary regression. The use of a first-order Taylor development leads to equation (11) for the logistic transition and to equation (12) for the exponential transition:

$$
\begin{aligned}
& F D_{i t}=\alpha_{i}+\theta_{0} T_{i t}+\theta_{1} T_{i t}^{2}+\epsilon_{i t}^{*} \\
& F D_{i t}=\alpha_{i}+\theta_{0} T_{i t}+\theta_{1} T_{i t}^{2}+\theta_{2} T_{i t}^{3}+\epsilon_{i t}^{*}
\end{aligned}
$$

In these auxiliary regressions, parameters $\theta_{1}$ and $\theta_{2}$ are proportional to the slope parameter $\gamma$ of the transition function. Thus, testing the linearity against the PSTR simply consists in testing $H_{0}: \theta_{1}=0$ in (11) for the logistic function and $H_{0}: \theta_{1}=\theta_{2}=0$ in (12) for the exponential transition. If we denote $S S R_{0}$ the panel sum of squared residuals under $H_{0}$, i.e. in the linear panel model with individual effects and $S S R_{1}$ the panel sum of squared residuals under $H_{1}$, i.e. in the transformed PSTR model with two regimes, the corresponding LM statistic is then defined by:

$$
L M=\frac{T N\left(S S R_{0}-S S R_{1}\right)}{S S R_{0}}
$$

where $N$ and $T$ denote the cross-section and time dimensions of the panel respectively. Under the null hypothesis, the LM statistic has an approximate $\chi^{2}(1)$ distribution for the logistic function and an approximate $\chi^{2}(2)$ distribution for the exponential function.

The method is similar when it comes to testing the number of transition functions in the model. We use a sequential approach by testing the null hypothesis of no remaining non-linearity. If the linearity hypothesis has been rejected, we then test whether there is one transition function $\left(H_{0}: r=1\right)$ or whether there are at least two transition functions $\left(H_{0}: r=2\right)$. Recall that a model with $r=2$ is defined as:

$$
F D_{i t}=\alpha_{i}+\beta_{0} T_{i t}+\beta_{1} T_{i t} g_{1}\left(T_{i t} ; \gamma_{1}, c_{1}\right)+\beta_{2} T_{i t} g_{2}\left(T_{i t} ; \gamma_{2}, c_{2}\right)+\epsilon_{i t}
$$

The procedure of test consists in replacing the second transition function by its first-order Taylor expansion around $\gamma_{2}=0$ and then in testing linear constraints on the parameters. If we use the first-order Taylor approximation of $g_{2}\left(T_{i t} ; \gamma_{2}, c_{2}\right)$, the LPSTR and EPSTR models become:

$$
\begin{aligned}
& F D_{i t}=\alpha_{i}+\beta_{0} T_{i t}+\beta_{1} T_{i t} g_{1}\left(T_{i t} ; \gamma_{1}, c_{1}\right)+\theta_{1} T_{i t}^{2}+\epsilon_{i t}^{*} \\
& F D_{i t}=\alpha_{i}+\beta_{0} T_{i t}+\beta_{1} T_{i t} g_{1}\left(T_{i t} ; \gamma_{1}, c_{1}\right)+\theta_{1} T_{i t}^{2}+\theta_{2} T_{i t}^{3}+\epsilon_{i t}^{*}
\end{aligned}
$$


and the test of no remaining non-linearity is simply defined by $H_{0}: \theta_{1}=0$ (LPSTR) or $H_{0}: \theta_{1}=\theta_{2}=0$ (EPSTR). Again, we use a LM test with $S S R_{0}$ the panel sum of squared residuals under $H_{0}$, i.e. in a PSTR model with one transition function and $S S R_{1}$ the sum of squared residuals of the transformed model.

The testing procedure is then as follows. Given a PSTR model with $r=r^{*}$, the null $H_{0}: r=r^{*}$ is tested against $H_{1}: r=r^{*}+1$. If $H_{0}$ is not rejected, the procedure ends. Otherwise, the null hypothesis $H_{0}: r=r^{*}+1$ is tested against $H_{1}: r=r^{*}+2$. The procedure continues until the first acceptance of $H_{0}$. Given the sequential aspect of this testing procedure, the significance level must be reduced by a constant factor $0<\rho<1$ at each step in order to avoid excessively large models. We assume $\rho=0.5$ as suggested by Gonzàlez et al. (2005).

\section{Threshold results}

This section presents the results of tests and estimation of the EPSTR and LPSTR specifications described previously. We consider the three filters $\mathrm{A}, \mathrm{B}$ and $\mathrm{C}$ and three alternative panels: the 15 countries, the 4 colder countries (Austria, Denmark, Finland and Sweden) and the 4 warmer countries (Greece, Italy, Portugal and Spain).

For each model, the first step is to test the linear specification of electricity consumption against a specification with threshold effects. If the linearity hypothesis is rejected, the second step will be to determine the number of transition functions required to capture all the non-linearity. The results of these linearity tests and specification tests of no remaining non-linearity are reported in Table 2 . For each specification, we calculate the $L M$ statistics for the linearity tests $\left(H_{0}: r=0\right.$ versus $\left.H_{1}: r=1\right)$ and for the no remaining non-linearity tests $\left(H_{0}: r=a\right.$ versus $\left.H_{1}: r=a+1\right)$. The values of the statistics are reported up to the first non rejection of $H_{0}$. We limit our analysis to a model with at most five transition functions. We justify this choice by two arguments. First, it reduces the computational costs of the estimation. Moreover, it does not affect (or only slightly affects) the estimates of the other threshold parameters and of the slope parameters in the existing regimes when a supplementary regime is introduced. 
The results of the testing procedure are reported in Table 2. Whatever the transition and the filter, the linearity tests clearly lead to the rejection of the null hypothesis of linearity of the relationship between electricity consumption and temperature. This first result confirms the non-linearity highlighted in the previous literature. The strongest rejection of the null hypothesis of linearity is obtained on the whole sample and particularly with the third filtering method. In contrast, the lowest value of the $L M$ statistic is attained for the sample of the cold countries. This may be due to the fact that the cold countries exhibit only the heating effect. Yet even in this case, the value of the test statistic is far below the critical value at standard levels.

The specification tests of no remaining non-linearity lead to the identification of an optimal number of transition functions in all cases. This number is always smaller than the maximum number of functions allowed in the algorithm, except for the EPSTR specification in the cold countries with the filter $\mathrm{B}^{12}$. In most other cases ${ }^{13}$, the optimal number of transition functions is smaller than two. In other words, a small number of extreme regimes is sufficient to capture the non-linearity of the relationship. However, recall that a smooth transition model, even with two extreme regimes $(r=1)$, can be viewed as a model with an infinite number of intermediate regimes. The coefficients are defined at each date and for each country as weighted averages of the values obtained in the two extreme regimes. The weights depend on the value of the transition function. So, even if $r=1$, this model allows a "continuum" of coefficient values (or regimes), each one associated with a different value of the transition function $g($.$) between 0$ and 1.

Tables 3, 4 and 5 contain the parameter estimates of the final PSTR models. As mentioned before, only the signs of the estimated parameters $\beta_{j}$ can be interpreted when there is one transition function. For instance, if we consider the Logistic PSTR model with $r=1$, the $\beta_{1}$ parameter is always positive, whereas the coefficient $\beta_{0}$ is negative. This merely implies that when the threshold variable (i.e. the temperature) increases, the link between electricity consumption and the temperature becomes less negative. For the highest temperatures, this link is positive. The analysis is slightly more complicated for the exponential function. The coefficient increases in the two situations, i.e. when the temper-

\footnotetext{
${ }^{12}$ This result could be due to the outliers obtained with the filter B as shown earlier.

${ }^{13}$ For all logistic specifications, only one transition is necessary.
} 
ature moves away from the location parameter value to either direction. This observation cannot be generalized in a model with more than one transition function $(r>1)$. Indeed no general result can be deduced here. It depends on the value of the slope parameters $\gamma_{j}$ and the location parameters $c_{j}$.

Turning to the slope parameters $\gamma_{j}$, we note that their estimated values are relatively small. This point is particularly important. Recall that when the slope parameter tends to infinity, the transition function tends to an indicator function for the LPSTR model and to one for the EPSTR model. Consequently, the transition functions are not sharp and the non-linearity of the energy demand cannot be reduced to a limited number of regimes. Indeed, a PSTR model with a smooth transition function can be interpreted as a model which allows a "continuum" of regimes. This "continuum" of regimes is clearly required when measuring the threshold effects of the energy consumption (as assumed in the non-parametric approach used in the first part of this paper).

The location parameters $c_{j}$ indicate the temperature level at which the transition function reaches an inflexion point. In the LPSTR models, one transition function is retained. In these specifications, the results are quite similar for the three filtering methods ${ }^{14}$. With the filter $\mathrm{C}$ for instance, we obtain a temperature of $16.1^{\circ} \mathrm{C}$ for all countries, $22.4^{\circ} \mathrm{C}$ for the warm countries and $14.7^{\circ} \mathrm{C}$ for the cold countries. At this level, two remarks can be made. First, the location parameter obtained is different from the value of $18.3^{\circ} \mathrm{C}$ generally admitted arbitrarily in the literature and changes with the countries under study. This point underlines one of the advantages of our approach as mentioned previously. The location parameters are not imposed but estimated. Second, we observe that the value is higher when the sample contains a more important part of warm countries. This result is rather intuitive.

In the EPSTR models where one transition function is retained, the value of the location parameter is $-5.0^{\circ}$. However, only $3.3 \%$ of temperature observations are lower than this threshold value. It implies that most observations of the threshold variable are in the right part of the U-shaped curve. For the threshold values superior to $-5.0^{\circ}$, this transition function has a shape relatively similar to a logistic function. The link between

\footnotetext{
${ }^{14}$ Nevertheless, the value of the location parameter obtained with the filter B is higher for all countries.
} 
electricity consumption and temperature becomes less negative for higher temperatures. The presence of observations in the left part of the curve implies that the variation of temperature interplays less on the electricity consumption when the temperature is very cold. Indeed, the coefficient becomes less negative when the temperature diminishes below $-5.0^{\circ}$. It means that the response of electricity consumption to additional decreases in the temperature level is less important when it is very cold (heating can not be increased infinitely). This effect cannot be taken into account with the LPSTR specification.

To better illustrate the difference in the results obtained with the EPSTR and LPSTR specifications, Figure 5 depicts the elasticities defined in equation (8) against temperature. For sake of parsimony, the results are reported only for the two specifications for filter $\mathrm{C}$ and for the whole panel. This figure confirms that the transition pattern implied by the logistic and exponential functions is identical for the temperatures superior to $-5.0^{\circ}$. However, for the EPSTR model, the elasticities increase below this temperature, reflecting the decrease in the sensitivity of the demand to the temperature. This Figure is also convenient to identify the zone where the consumption is inelastic to the temperature. For both specifications, the elasticities equal to zero around $16^{\circ} \mathrm{C}$.

Unfortunately, we are not able to pursue the analysis of the location parameter influence in the EPSTR models with several transition functions, because we do not know the "theoretical shape" of the transition in these kinds of specifications. We have represented the estimated electricity consumption as in Moral-Carcedo and Vicéns-Otero (2005). One alternative solution would have consisted in plotting the transition function against the threshold variable.

Figure 6 displays the estimated electricity mean consumption ${ }^{15}$ derived from the EPSTR and LPSTR models (equations 4 and 6 or 7) for the observed values of the threshold variable (i.e. the temperature). This exercise is repeated for the three filtering methods and the three groups of countries. The results imply several remarks. First, whatever the choice of the filtering method or of the model, the graphs are fairly similar. More precisely, the estimated consumption is of the same magnitude and the inflexion points are located in

\footnotetext{
${ }^{15} \mathrm{We}$ do not consider the fixed effects since it only affects the level of the estimated consumption for a country and not the relation between electrical consumption and temperature.
} 
a similar way. It means that the characterization of the relationship between temperature and electricity consumption is robust to the choice of the filter. It also shows that the PSTR model is so flexible that different specifications with different transition functions give qualitatively and quantitatively similar results for most temperatures. Second, in the same way, the analysis of the consumption on sub-samples does not amend the results. Indeed, even if it is no clear to the first reading due to the scale, considering the warm and cold countries is equivalent to studying the whole sample. This work on sub-samples acts like a zoom, and shows that a PSTR model provides a simple parametric approach to capture cross-country heterogeneity ${ }^{16}$. This point is interesting, because heterogeneity is a recurrent issue in panel data.

As far as the impact of temperature on electricity consumption is concerned, we can make the following remarks. Figure 6 shows that only the heating effect prevails in the cold countries: when the temperature increases, the consumption decreases. It confirms our intuition about the low rejection of the linearity hypothesis for this group of countries. In contrast, the warm countries exhibit the two opposite effects: the heating and the cooling effects. In particular, there is a strong positive link between electricity consumption and summer temperatures. These observations can be used to infer about the potential impact of climate change in the different European countries. An increase in the average yearly temperature could be associated with a rising electricity demand in the warm countries exhibiting the two effects, whereas it should diminish the electricity use in colder area. To have a closer look at the influence of climatic change on electricity use in Europe, we compare in the following the estimated consumption at different dates by using rolling regressions.

Given the increase in temperature observed over the period under study ${ }^{17}$, we can assess the potential impact of climate change on electricity consumption in the European countries. To this aim, a small experiment based on rolling regressions is conducted. The EPSTR specification is re-estimated on three overlapping sub-periods of five years ${ }^{18}$.

\footnotetext{
${ }^{16}$ A similar result is obtained by Destais, Fouquau and Hurlin (2007).

${ }^{17}$ See Table 1.

${ }^{18}$ For the sake of parsimony, we do not report the corresponding estimates and the test results and the LPSTR result, but they are available from the authors on request.
} 
Relying on the results of the linearity tests, we choose to present the results obtained with the third filter and for two groups of countries: the whole panel and the group of warm countries. The panel of cold countries is not considered since the mean temperature diminishes from the second to the third sub-period (see Table 1). Results are depicted in Figure 7. Several results are worth commenting on. First, we note general increase in the consumption regardless of the temperature level. This effect is particularly important in the warm countries. We also note a higher cooling effect on the last sub-period especially in the warm countries where the estimated consumption is sharper for the highest temperatures at the end of the period. In contrast, no cooling effect appears at the beginning of the period since the cooling devices were not as developed as today. Hence we find a higher sensitivity of the electricy consumption in the summer period. This change of beviours may be due to the increase of the temperatures observed over the last two decades.

\section{Conclusion}

In this paper, we have examined the relationship between electricity demand and temperature in Europe. Using a panel threshold model applied to 15 European countries over the last two decades, we have confirmed the non-linear pattern of this relationship found in more limited geographical areas in earlier studies. Moreover rolling regressions show the change of electricity use in Europe especially in the warm countries. The sensitivity of the demand is higher in the recent period.

These results are robust to the kind of treatment of the non climatic seasonality component and to the choice of the panel even if the non-linearity is found more pronounced in the South countries. The application of an Exponential panel threshold specification also provides a more accurate characterization of the relationship especially for the coldest temperatures. However, the results are fairly similar to those obtained with the logistic function given the flexibility of the two specifications. Hence, the use of both models gives an additional check of the robustness of our results.

In sum, this paper shows that temperature is a major determinant of electricity consumption in Europe and that the relationship between the two variables is modified by the climate change. Given the concern about global warming, these findings support the 
renewed interest in energy related questions by the European policymakers.

\section{References}

Al-Zayer J., Al-Ibrahim A.A., 1996. Modelling the impact of the temperature on electricity consumption in Eastern province of Saudi Arabia. Journal of Forecasting 15, 97-106.

Amato A.D., Ruth M., Kirshen P., Horwitz J., 2005. Regional energy demand response to climate change: Methodology and application to the commonwealth of Massachusetts. Climate Change 71, 175-201.

Beenstock M., Goldin E., Nabot D., 1999. The demand for electricity in Israel. Energy Economics 21, 168-183.

Bigano A., Bosello F., Marano G., 2006. Energy demand and temperature: A dynamic panel analysis. FEEM working paper No. 112.2006.

Colletaz G, Hurlin C., 2006. Threshold effects in the public capital productivity: an international panel smooth transition approach, Document de Recherche du Laboratoire d'Economie d'Orléans, 2006-1.

Davies R.B., 1987. Hypothesis testing when a nuisance parameter is present only under the alternative. Biometrika 74, 33-43.

De Cian E., Lanzi E., Roson R., 2007. The impact of temperature change on energy demand: a dynamic panel analysis. FEEM Working Paper No. 46.2007.

Destais G., Fouquau J., Hurlin C., 2007. Energy development and energy intensity: A panel data analysis. In: Keppler J.H., Bourbonnais R., Girod J. (Eds), The Econometrics of Energy Systems, Palgrave, p. 98-120.

González A., Teräsvirta T., van Dijk D., 2005. Panel smooth transition regression models. SEE/EFI Working Paper Series in Economics and Finance, No. 604.

Li X., Sailor D.J., 1995. Electricity use sensitivity to climate and climate change. World Resource Review 7, 334-346.

Mitchell T.D., Carter T.R., Jones P.D., Hulme M., New M., 2004. A comprehensive set of high-resolution grids of monthly climate for Europe and the globe: the observed record (1901-2000) and 16 scenarios (2001-2100).Tyndall Centre Working Paper No. 55.

Moral-Carcedo J., Vicéns-Otero J., 2005. Modeling the non-linear response of Spanish electricity demand to temperature variations. Energy Economics 27, 477-494. 
Pardo A., Meneu V., Valor E., 2002. Temperature and seasonality influences on Spanish electricity load. Energy Economics 24, 55-70.

Sailor D.J., 2001. Relating residential and commercial sector electricity loads to climate - evaluating state level sensitivities and vulnerabilities. Energy 26, 645-657.

Sailor D.J., Munõz J.R., 1997. Sensitivity of electricity and natural gas consumption to climate in the USA - methodology and results for eight states. Energy 22, 987-998.

Valor E., Meneu V., Caselles V., 2001. Daily air temperature and electricity load in Spain. Journal of Applied Meteorology 408, 1413-1421.

Zachariadis T., Pashourtidou N., 2007. An empirical analysis of electricity consumption in Cyprus. Energy Economics 29, 183-198. 
Table 1: Descriptive statistics on temperature data

\begin{tabular}{|c|c|c|c|c|c|c|c|}
\hline \hline \multirow{2}{*}{ Country } & \multicolumn{5}{|c|}{ Mean } & \multirow{2}{*}{ Min } & \multirow{2}{*}{ Max } \\
\cline { 2 - 5 } & $1985-2000$ & $1985-90$ & $1990-95$ & $1995-2000$ & & & \\
\hline \hline Finland & 2,16 & 1,73 & 2,54 & 2,46 & $-20,4$ & 18,2 & 9,28 \\
\hline Sweden & 2,6 & 2,19 & 2,99 & 2,86 & $-16,8$ & 16,2 & 8,03 \\
\hline Austria & 6,88 & 6,59 & 7,12 & 6,90 & -8 & 19 & 6,98 \\
\hline Denmark & 7,89 & 7,61 & 8,29 & 8,02 & $-6,5$ & 19,5 & 6,27 \\
\hline United Kingdom & 8,76 & 8,49 & 8,85 & 9,10 & $-0,4$ & 16,7 & 4,11 \\
\hline Germany & 8,97 & 8,70 & 9,28 & 9,10 & $-6,2$ & 21,3 & 6,53 \\
\hline Luxembourg & 9,22 & 8,86 & 9,54 & 9,47 & -5 & 21,4 & 6,23 \\
\hline Ireland & 9,61 & 9,30 & 9,70 & 9,96 & 1,3 & 16,6 & 3,67 \\
\hline Netherlands & 9,72 & 9,45 & 9,95 & 9,95 & $-3,7$ & 20,2 & 5,42 \\
\hline Belgium & 10,08 & 9,79 & 10,35 & 10,32 & $-3,9$ & 21,1 & 5,78 \\
\hline France & 11,22 & 10,97 & 11,40 & 11,47 & -1 & 21,4 & 5,65 \\
\hline Italy & 13,92 & 13,80 & 13,96 & 14,01 & 3,5 & 24,6 & 6,11 \\
\hline Spain & 13,95 & 13,91 & 13,93 & 14,18 & 3,9 & 24,3 & 5,93 \\
\hline Greece & 15,45 & 15,34 & 15,33 & 15,72 & 4,8 & 26,7 & 6,65 \\
\hline Portugal & 15,63 & 15,65 & 15,62 & 15,79 & 7,6 & 24,6 & 4,81 \\
\hline \hline
\end{tabular}


Table 2: $L M$ Tests for Remaining Non-linearity

\begin{tabular}{|c|c|c|c|c|c|c|}
\hline \multirow{3}{*}{$\begin{array}{l}\text { Sample } \\
\text { Transition Function }\end{array}$} & \multicolumn{6}{|c|}{ Filter A } \\
\hline & \multicolumn{2}{|c|}{ All Countries } & \multicolumn{2}{|c|}{ Warm Countries } & \multicolumn{2}{|c|}{ Cold Countries } \\
\hline & EPSTR & LPSTR & EPSTR & LPSTR & EPSTR & LPSTR \\
\hline $\mathrm{H} 0: \mathrm{r}=0$ vs $\mathrm{H} 1: \mathrm{r}=1$ & $\begin{array}{l}806.3 \\
(0.00)\end{array}$ & $\begin{array}{l}740.2 \\
(0.00)\end{array}$ & $\begin{array}{l}304.9 \\
(0.00)\end{array}$ & $\begin{array}{l}292.2 \\
(0.00)\end{array}$ & $\begin{array}{l}77.47 \\
(0.00)\end{array}$ & $\begin{array}{l}31.63 \\
(0.00)\end{array}$ \\
\hline $\mathrm{H} 0: \mathrm{r}=1$ vs $\mathrm{H} 1: \mathrm{r}=2$ & $\begin{array}{l}0.188 \\
(0.91)\end{array}$ & $\begin{array}{l}3.31 \\
(0.07)\end{array}$ & $\begin{array}{l}224.3 \\
(0.00)\end{array}$ & $\begin{array}{l}0.706 \\
(0.79)\end{array}$ & $\begin{array}{l}42.9 \\
(0.00)\end{array}$ & $\begin{array}{l}3.949 \\
(0.05)\end{array}$ \\
\hline H0 $: r=2$ vs H1 $: r=3$ & - & - & $\begin{array}{l}10.74 \\
(0.04)\end{array}$ & - & $\begin{array}{l}0.007 \\
(0.99)\end{array}$ & - \\
\hline \multirow[t]{2}{*}{ H0 $: r=3$ vs H1 $: r>3$} & - & - & $\begin{array}{c}0.013 \\
(0.91) \\
\end{array}$ & - & - & - \\
\hline & \multicolumn{6}{|c|}{ Filter B } \\
\hline Sample & \multicolumn{2}{|c|}{ All Countries } & \multicolumn{2}{|c|}{ Warm Countries } & \multicolumn{2}{|c|}{ Cold Countries } \\
\hline Transition Function & EPSTR & LPSTR & EPSTR & LPSTR & EPSTR & LPSTR \\
\hline $\mathrm{H} 0: \mathrm{r}=0$ vs $\mathrm{H} 1: \mathrm{r}=1$ & $\begin{array}{l}762.4 \\
(0.00)\end{array}$ & $\begin{array}{l}685.5 \\
(0.00)\end{array}$ & $\begin{array}{l}98.43 \\
(0.00)\end{array}$ & $\begin{array}{l}94.05 \\
(0.00)\end{array}$ & $\begin{array}{l}70.33 \\
(0.00)\end{array}$ & $\begin{array}{l}23.43 \\
(0.00)\end{array}$ \\
\hline H0 $: r=1$ vs $\mathrm{H} 1: r=2$ & $\begin{array}{l}96.79 \\
(0.00)\end{array}$ & $\begin{array}{l}1.474 \\
(0.22)\end{array}$ & $\begin{array}{l}85.70 \\
(0.00)\end{array}$ & $\begin{array}{l}0.192 \\
(0.66)\end{array}$ & $\begin{array}{l}68.18 \\
(0.00)\end{array}$ & $\begin{array}{l}0.485 \\
(0.49)\end{array}$ \\
\hline $\mathrm{H} 0: \mathrm{r}=2$ vs $\mathrm{H} 1: \mathrm{r}=3$ & $\begin{array}{l}6.265 \\
(0.04)\end{array}$ & - & $\begin{array}{l}4.187 \\
(0.12)\end{array}$ & - & $\begin{array}{l}71.47 \\
(0.00)\end{array}$ & - \\
\hline H0 $: r=3$ vs H1 $: r=4$ & - & - & - & - & $\begin{array}{l}71.09 \\
(0.00)\end{array}$ & - \\
\hline $\mathrm{H} 0: \mathrm{r}=4$ vs $\mathrm{H} 1: \mathrm{r}=5$ & - & - & - & - & $\begin{array}{l}48.5 \\
(0.00)\end{array}$ & - \\
\hline $\mathrm{H} 0: \mathrm{r}=5$ vs $\mathrm{H} 1: \mathrm{r}>5$ & - & - & - & - & $\begin{array}{l}12.74 \\
(0.00)\end{array}$ & - \\
\hline
\end{tabular}

\begin{tabular}{|c|c|c|c|c|c|c|}
\hline \multirow{3}{*}{$\begin{array}{l}\text { Sample } \\
\text { Transition Function }\end{array}$} & \multicolumn{6}{|c|}{ Filter C } \\
\hline & \multicolumn{2}{|c|}{ All Countries } & \multicolumn{2}{|c|}{ Warm Countries } & \multicolumn{2}{|c|}{ Cold Countries } \\
\hline & EPSTR & LPSTR & EPSTR & LPSTR & EPSTR & LPSTR \\
\hline $\mathrm{H} 0: \mathrm{r}=0$ vs $\mathrm{H} 1: \mathrm{r}=1$ & $\begin{array}{l}1058 \\
(0.00)\end{array}$ & $\begin{array}{c}988 \\
(0.00)\end{array}$ & $\begin{array}{l}331.5 \\
(0.00)\end{array}$ & $\begin{array}{l}316.0 \\
(0.00)\end{array}$ & $\begin{array}{l}164.7 \\
(0.00)\end{array}$ & $\begin{array}{l}90.0 \\
(0.00)\end{array}$ \\
\hline $\mathrm{H} 0: \mathrm{r}=1$ vs $\mathrm{H} 1: \mathrm{r}=2$ & $\begin{array}{l}1.286 \\
(0.52)\end{array}$ & $\begin{array}{l}3.58 \\
(0.06)\end{array}$ & $\begin{array}{l}266.9 \\
(0.00)\end{array}$ & $\begin{array}{l}0.161 \\
(0.69)\end{array}$ & $\begin{array}{l}75.21 \\
(0.00)\end{array}$ & $\begin{array}{l}2.271 \\
(0.13)\end{array}$ \\
\hline $\mathrm{H} 0: \mathrm{r}=2$ vs $\mathrm{H} 1: \mathrm{r}=3$ & - & - & $\begin{array}{l}26.06 \\
(0.00)\end{array}$ & - & $\begin{array}{l}17.94 \\
(0.00)\end{array}$ & - \\
\hline $\mathrm{H} 0: \mathrm{r}=3$ vs $\mathrm{H} 1: \mathrm{r}=4$ & - & - & $\begin{array}{l}0.050 \\
(0.97)\end{array}$ & - & $\begin{array}{l}17.76 \\
(0.00)\end{array}$ & - \\
\hline $\mathrm{H} 0: \mathrm{r}=4$ vs $\mathrm{H} 1: \mathrm{r}=5$ & - & - & - & - & $\begin{array}{l}19.36 \\
(0.00)\end{array}$ & - \\
\hline $\mathrm{H} 0: \mathrm{r}=5$ vs $\mathrm{H} 1: \mathrm{r}>5$ & - & - & - & - & $\begin{array}{l}0.100 \\
(0.95)\end{array}$ & - \\
\hline
\end{tabular}

Notes: For each model, the testing procedure works as follows. First, the linear model $(r=0)$ is tested against a model with one threshold $(r=1)$. If the null hypothesis is rejected, the single threshold model is tested against a double threshold model $(r=2)$. The procedure is continued until the hypothesis of no additional threshold is not rejected. The corresponding $L M$ statistic has an asymptotic $\chi^{2}(1)$ distribution under $H_{0}$ for a Logistic function and an asymptotic $\chi^{2}(2)$ distribution under $H_{0}$ for an Exponential function. The corresponding p-values are reported in parentheses. 
Table 3: Parameter Estimates for the Final PSTR Models

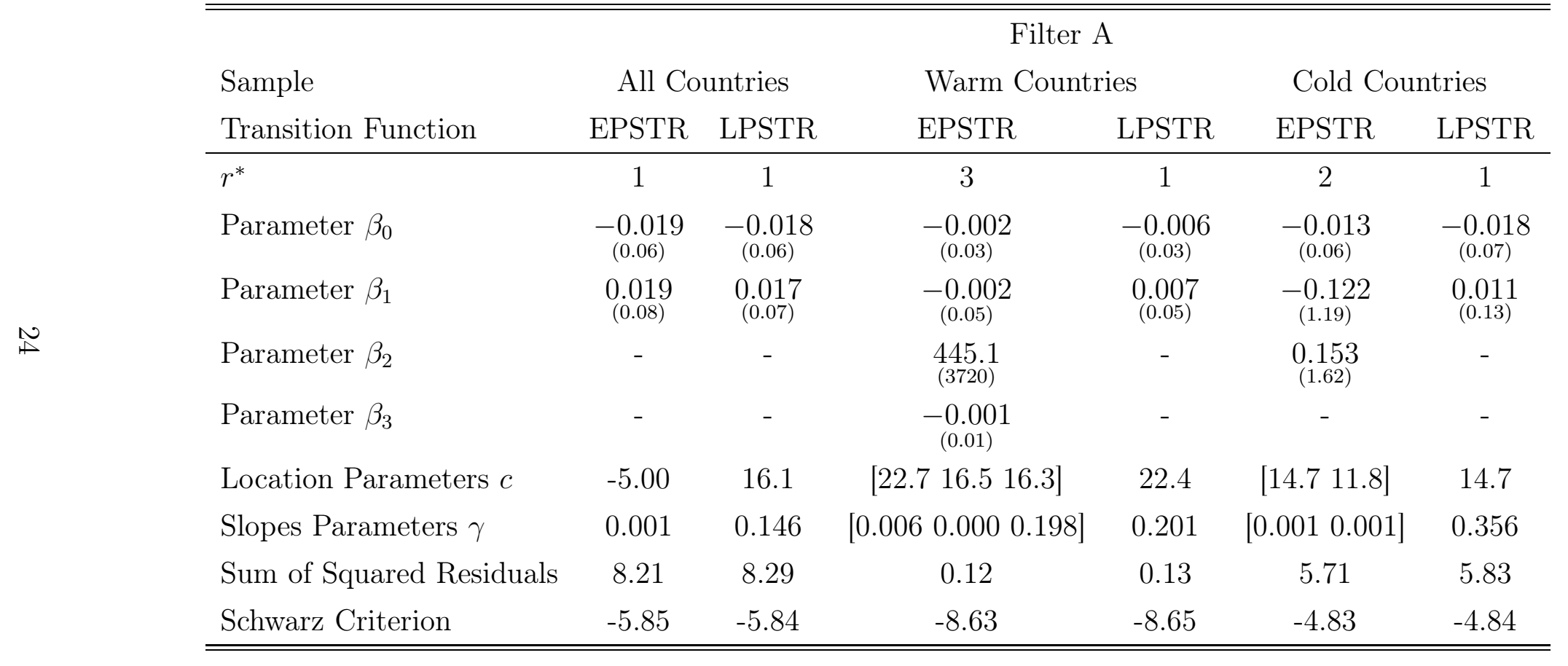

Notes: The standard errors in parentheses are in percent and corrected for heteroskedasticity. For each model, the number of transition functions $r$ is determined by a sequential testing procedure (see Table 2). For each transition function, the estimated location parameters $c$ and the corresponding estimated slope parameter $\gamma$ are reported. The PSTR parameters can not be directly interpreted as elasticities. 
Table 4: Parameter Estimates for the Final PSTR Models

\begin{tabular}{|c|c|c|c|c|c|c|}
\hline \multirow{3}{*}{$\begin{array}{l}\text { Sample } \\
\text { Transition Function }\end{array}$} & \multicolumn{6}{|c|}{ Filter B } \\
\hline & \multicolumn{2}{|c|}{ All Countries } & \multicolumn{2}{|c|}{ Warm Countries } & \multicolumn{2}{|l|}{ Cold Countries } \\
\hline & EPSTR & LPSTR & EPSTR & LPSTR & EPSTR & LPSTR \\
\hline$r^{*}$ & 2 & 1 & 2 & 1 & 5 & 1 \\
\hline Parameter $\beta_{0}$ & $\begin{array}{c}-0.007 \\
(0.19)\end{array}$ & $\begin{array}{c}-0.020 \\
(0.06)\end{array}$ & $\begin{array}{l}-0.003 \\
(0.07)\end{array}$ & $\begin{array}{l}-0.212 \\
(2.24)\end{array}$ & $\begin{array}{c}-0.014 \\
(0.17)\end{array}$ & $\begin{array}{c}-0.018 \\
(0.05)\end{array}$ \\
\hline Parameter $\beta_{1}$ & $\begin{array}{c}-0.54 \\
(3.02)\end{array}$ & $\begin{array}{c}0.023 \\
(0.10)\end{array}$ & $\begin{array}{c}-22.2 \\
(670)\end{array}$ & $\begin{array}{l}0.418 \\
(4.44)\end{array}$ & $\begin{array}{l}4.36 \\
(239)\end{array}$ & $\begin{array}{c}0.007 \\
(0.17)\end{array}$ \\
\hline Parameter $\beta_{2}$ & $\begin{array}{l}0.52 \\
(3.02)\end{array}$ & - & $\begin{array}{l}848.8 \\
(8756)\end{array}$ & - & $\begin{array}{c}-5.55 \\
(307)\end{array}$ & - \\
\hline Parameter $\beta_{3}$ & - & - & - & - & $\frac{1.188}{(67.4)}$ & - \\
\hline Parameter $\beta_{4}$ & - & - & - & - & $\begin{array}{c}-0.186 \\
(2.17)\end{array}$ & - \\
\hline Parameter $\beta_{5}$ & - & - & - & - & $\underset{(2.18)}{0.182}$ & - \\
\hline Location Parameters $c$ & {$\left[\begin{array}{ll}22.7 & 22.6\end{array}\right]$} & 21.2 & {$\left[\begin{array}{lll}22.6 & 18.0\end{array}\right]$} & 22.4 & {$\left[\begin{array}{lllll}14.3 & 14.3 & 14.3 & 14.6 & 14.7\end{array}\right]$} & 14.7 \\
\hline Slopes Parameters $\gamma$ & {$\left[\begin{array}{ll}0.006 & 0.006\end{array}\right]$} & 0.111 & {$\left[\begin{array}{ll}0.000 & 0.000\end{array}\right]$} & 0.003 & {$\left[\begin{array}{lllll}9.75 & 9.97 & 10.8 & 0.037 & 0.039\end{array}\right]$} & 1.595 \\
\hline Sum of Squared Residuals & 9.19 & 9.20 & 0.415 & 0.418 & 5.23 & 5.33 \\
\hline Schwarz Criterion & -5.72 & -5.73 & -7.45 & -7.47 & -4.83 & -4.92 \\
\hline
\end{tabular}

Notes: The standard errors in parentheses are in percentage and corrected for heteroskedasticity. For each model, the number of transition functions $r$ is determined by a sequential testing procedure (see Table 2). For each transition function, the estimated location parameters $c$ and the corresponding estimated slope parameter $\gamma$ are reported. The PSTR parameters can not be directly interpreted as elasticities. 
Table 5: Parameter Estimates for the Final PSTR Models

\begin{tabular}{|c|c|c|c|c|c|c|}
\hline \multirow{3}{*}{$\begin{array}{l}\text { Sample } \\
\text { Transition Function }\end{array}$} & \multicolumn{6}{|c|}{ Filter $\mathrm{C}$} \\
\hline & \multicolumn{2}{|c|}{ All Countries } & \multicolumn{2}{|c|}{ Warm Countries } & \multicolumn{2}{|l|}{ Cold Countries } \\
\hline & EPSTR & LPSTR & EPSTR & LPSTR & EPSTR & LPSTR \\
\hline$r^{*}$ & 1 & 1 & 3 & 1 & 5 & 1 \\
\hline Parameter $\beta_{0}$ & $\begin{array}{c}-0.020 \\
(0.06)\end{array}$ & $\begin{array}{c}-0.020 \\
(0.06)\end{array}$ & $\begin{array}{c}-0.004 \\
(0.06)\end{array}$ & $-\underset{(0.03)}{-0.006}$ & $\begin{array}{c}-0.014 \\
(1.39)\end{array}$ & $\begin{array}{c}-0.018 \\
(0.05)\end{array}$ \\
\hline Parameter $\beta_{1}$ & $\begin{array}{c}0.020 \\
(0.07)\end{array}$ & $\begin{array}{l}0.020 \\
(0.07)\end{array}$ & $\begin{array}{c}-427.5 \\
(3956)\end{array}$ & $\begin{array}{l}0.008 \\
(0.04)\end{array}$ & $\begin{array}{l}0.240 \\
(2.99)\end{array}$ & $\begin{array}{c}0.007 \\
(0.17)\end{array}$ \\
\hline Parameter $\beta_{2}$ & - & - & $\underset{(0.23)}{-0.013}$ & - & $\begin{array}{l}-0.246 \\
(3.17)\end{array}$ & - \\
\hline Parameter $\beta_{3}$ & - & - & $\begin{array}{l}-0.026 \\
(0.36)\end{array}$ & - & $\underset{(0.12)}{-0.001}$ & - \\
\hline Parameter $\beta_{4}$ & - & - & - & - & $\begin{array}{c}-0.030 \\
(1.39)\end{array}$ & - \\
\hline Parameter $\beta_{5}$ & - & - & - & - & $\begin{array}{c}0.035 \\
(0.25)\end{array}$ & - \\
\hline Location Parameters $c$ & -5.0 & 16.1 & {$\left[\begin{array}{llll}22.7 & 17.8 & 18.1\end{array}\right]$} & 22.4 & {$\left[\begin{array}{lllll}8.20 & 7.74 & 13.5 & -1.43 & -2.05\end{array}\right]$} & 13.5 \\
\hline Slopes Parameters $\gamma$ & 0.001 & 0.131 & {$\left[\begin{array}{lll}0.000 & 0.020 & 0.011\end{array}\right]$} & 0.187 & {$\left[\begin{array}{lllll}0.012 & 0.010 & 4.33 & 12.9 & 0.016\end{array}\right]$} & 0.496 \\
\hline Sum of Squared Residuals & 6.26 & 6.32 & 0.121 & 0.129 & 3.79 & 4.01 \\
\hline Schwarz Criterion & -6.12 & -6.11 & -8.65 & -8.65 & -5.15 & -5.21 \\
\hline
\end{tabular}

Notes: The standard errors in parentheses are in percentage and corrected for heteroskedasticity. For each model, the number of transition functions $r$ is determined by a sequential testing procedure (see Table 2). For each transition function, the estimated location parameters $c$ and the corresponding estimated slope parameter $\gamma$ are reported. The PSTR parameters can not be directly interpreted as elasticities. 
Figure 1: Filtered demand versus temperature (filter A)
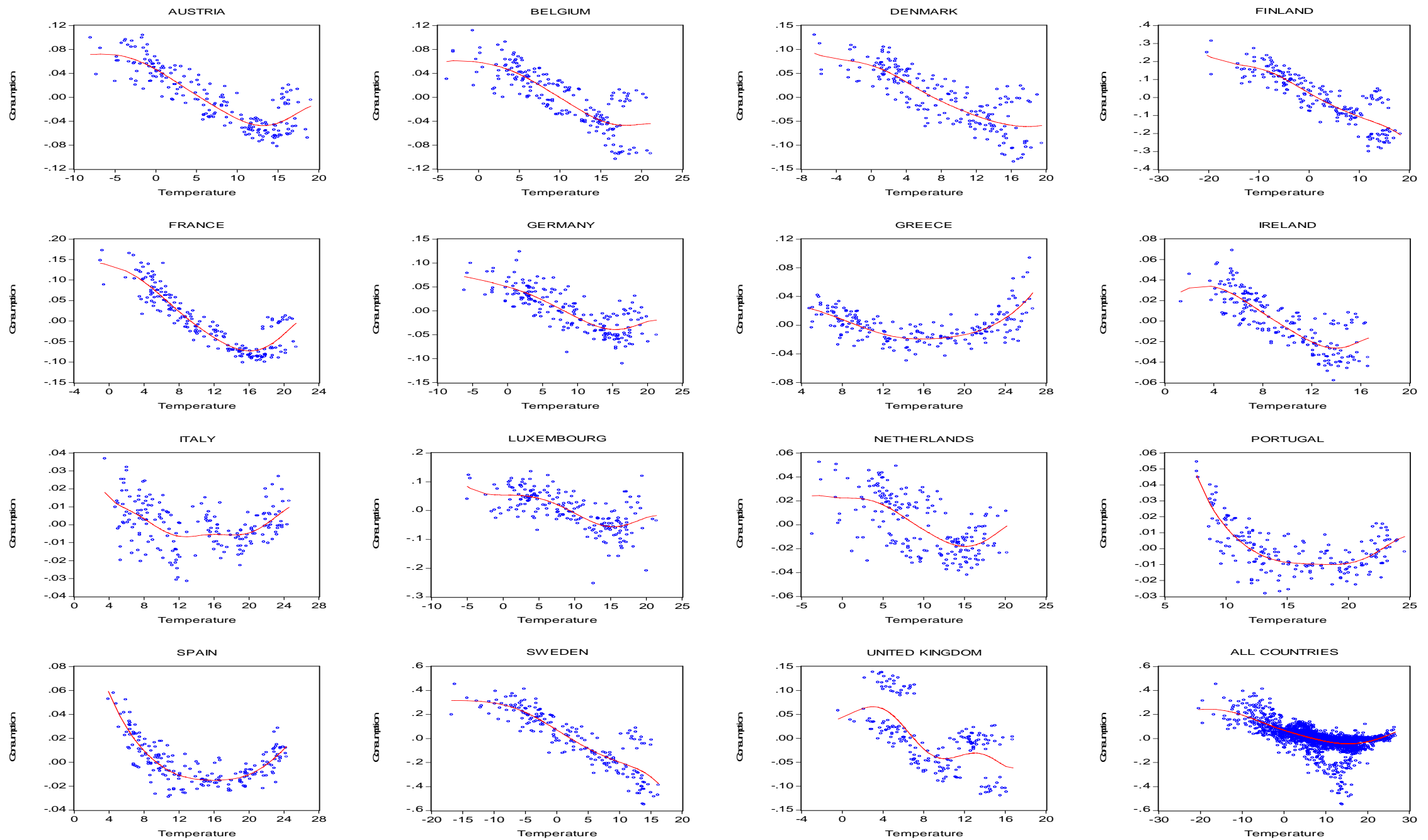

Notes: The continuous line depicts a local polynomial kernel regression of order 2 with a Gaussian kernel between the two variables 
Figure 2: Filtered demand versus temperature (filter B)
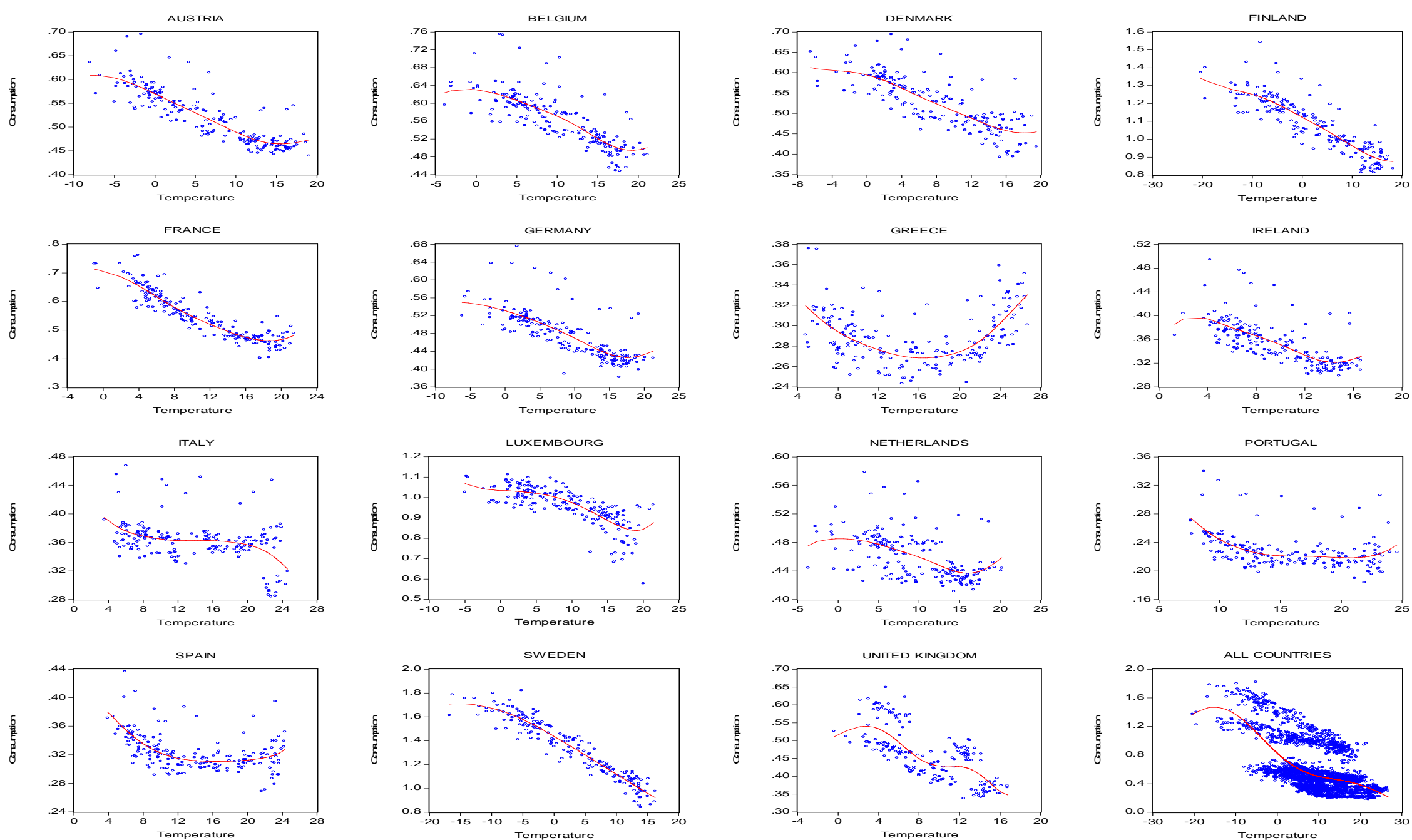

Notes: The continuous line depicts a local polynomial kernel regression of order 2 with a Gaussian kernel between the two variables 
Figure 3: Filtered demand versus temperature (filter C)
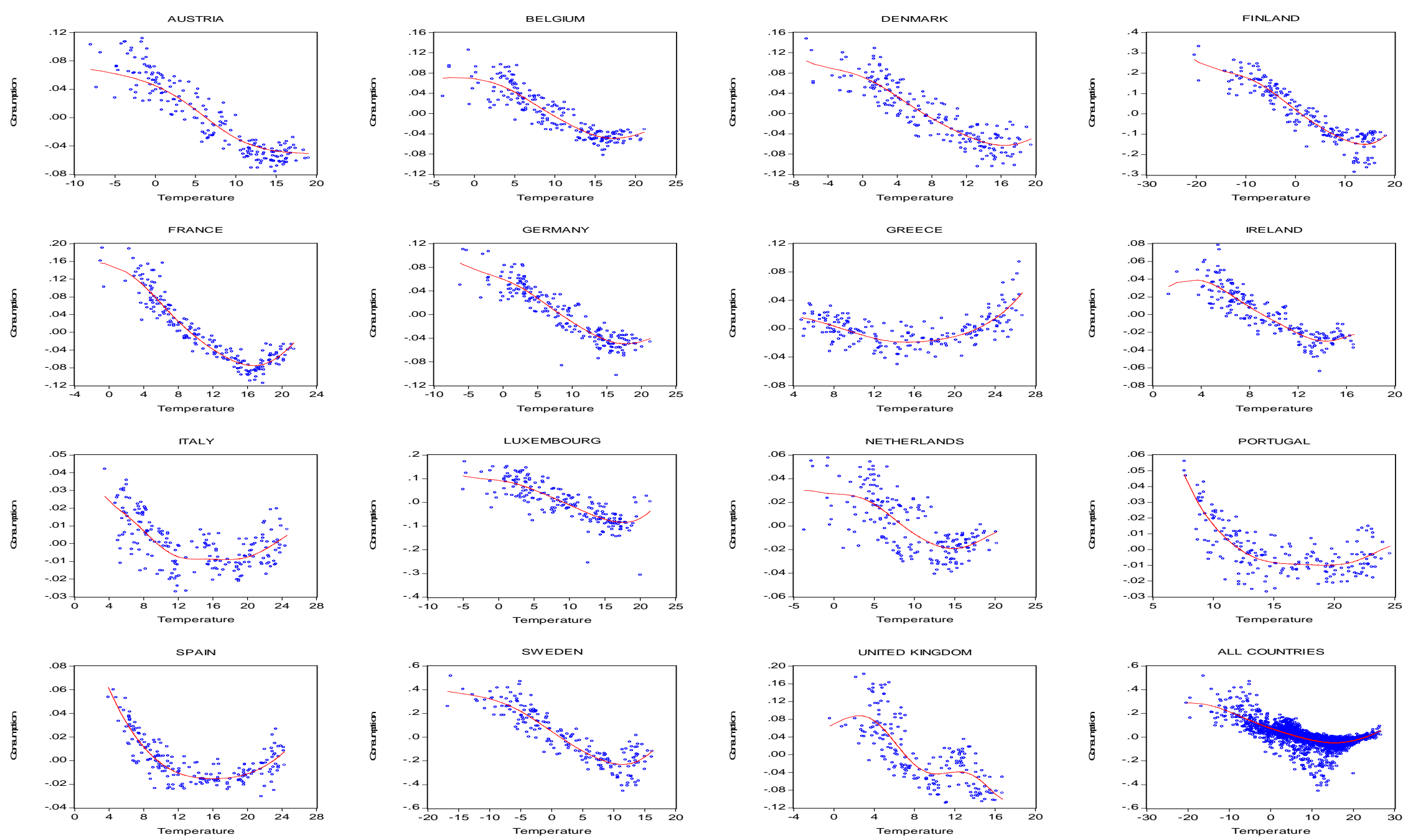
Figure 4: Transition Function with $\mathrm{c}=0$ with different values of the slope parameter $\gamma$
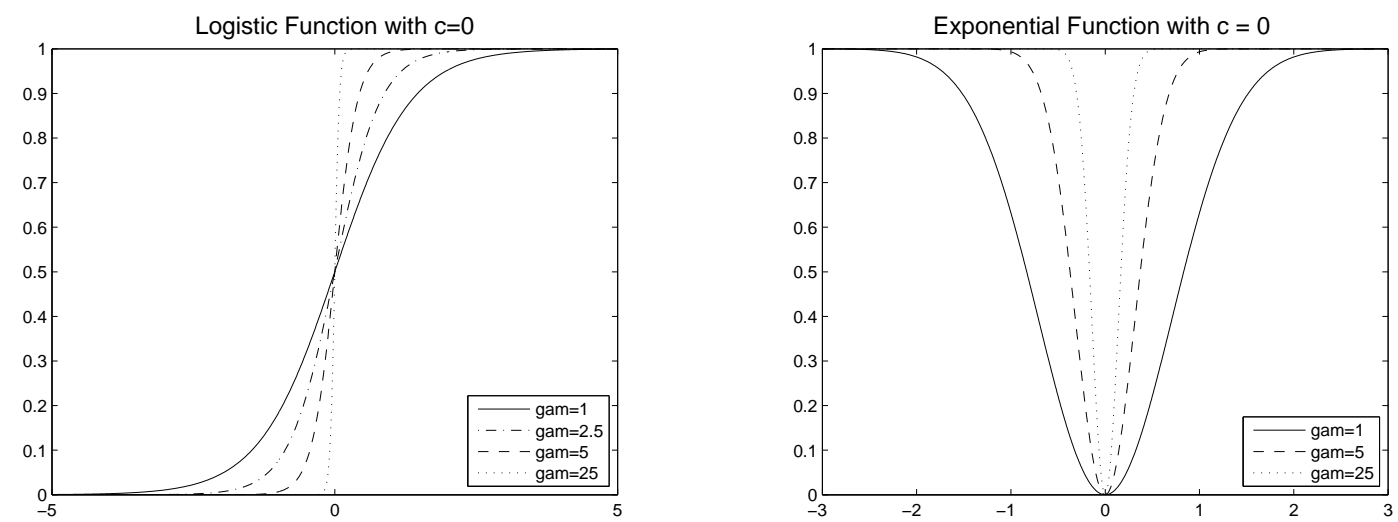

Figure 5: Elasticties of electricity consumption to the temperature
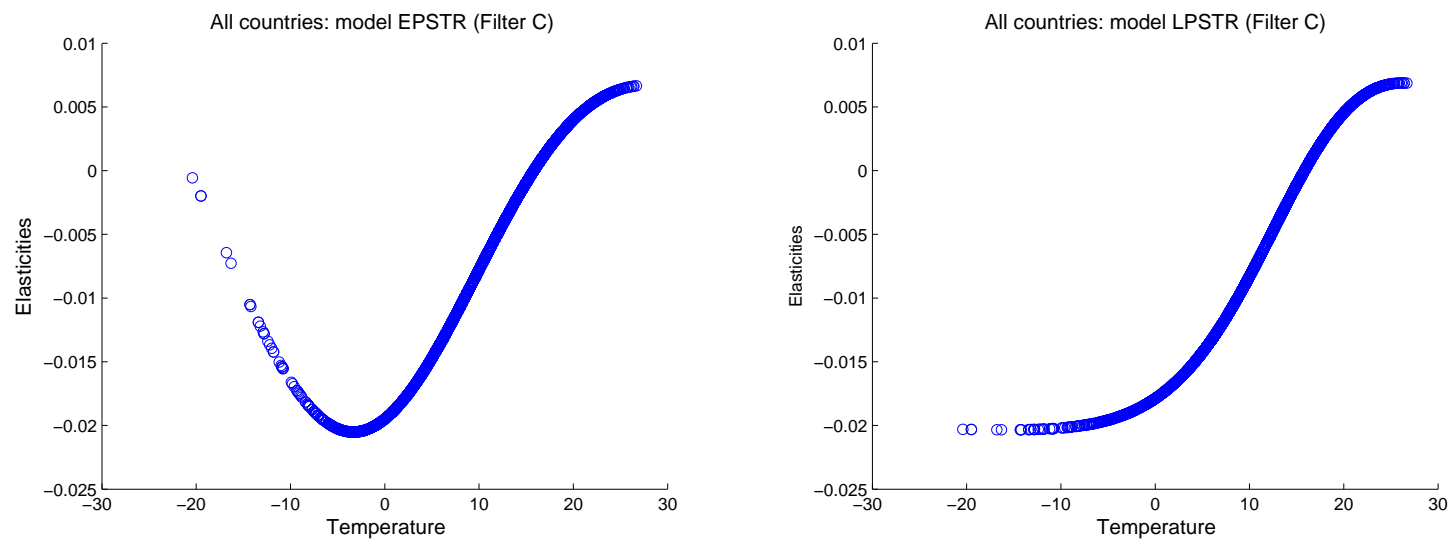
Figure 6: Estimated electricity mean consumption with PSTR models
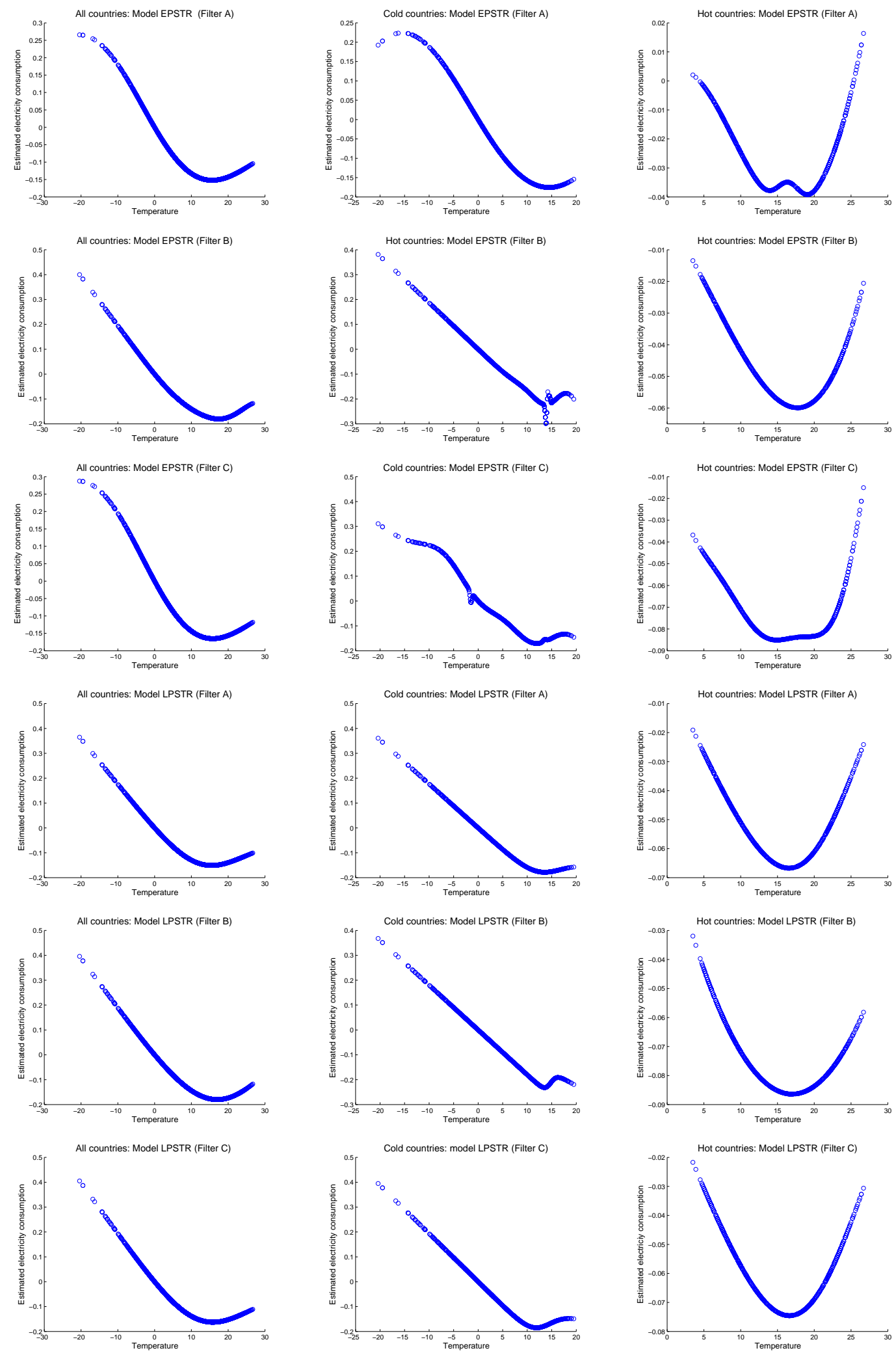
Figure 7: Estimated electricity consumption with rolling regression

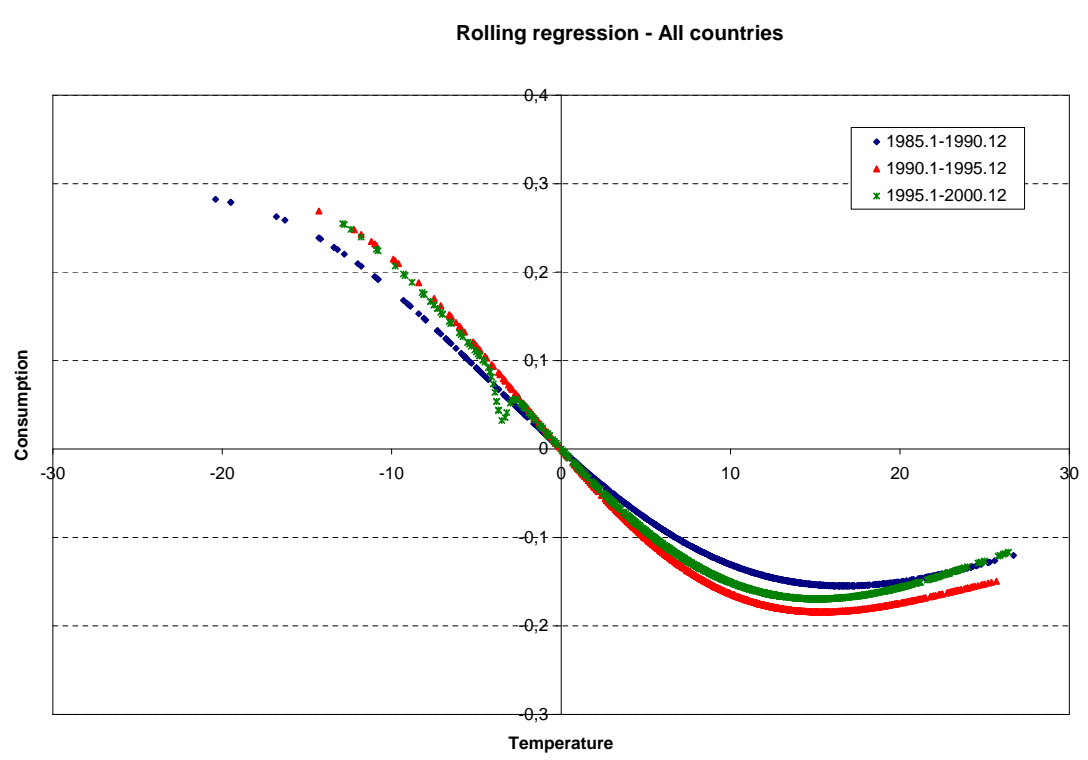

Rolling regression - Hot countries

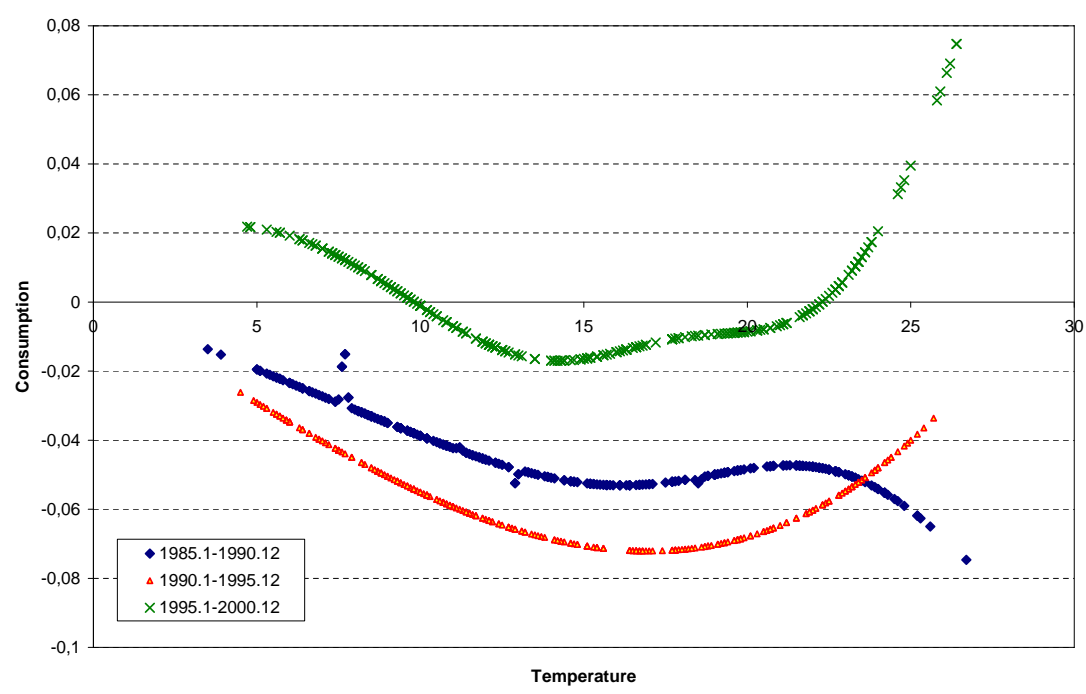

